\title{
A systematic review of online resources to support patient decision-making for full-thickness rectal prolapse surgery
}

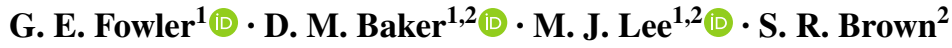

Received: 24 August 2017 / Accepted: 19 September 2017 / Published online: 3 November 2017

(C) The Author(s) 2017. This article is an open access publication

\begin{abstract}
Background The internet is becoming an increasingly popular resource to support patient decision-making outside of the clinical encounter. The quality of online health information is variable and largely unregulated. The aim of this study was to assess the quality of online resources to support patient decision-making for full-thickness rectal prolapse surgery.

Methods This systematic review was registered on the PROSPERO database (CRD42017058319). Searches were performed on Google and specialist decision aid repositories using a pre-defined search strategy. Sources were analysed according to three measures: (1) their readability using the Flesch-Kincaid Reading Ease score, (2) DISCERN score and (3) International Patient Decision Aids Standards (IPDAS) minimum standards criteria score (IPDASi, v4.0). Results Overall, 95 sources were from Google and the specialist decision aid repositories. There were 53 duplicates removed, and 18 sources did not meet the pre-defined eligibility criteria, leaving 24 sources included in the fulltext analysis. The mean Flesch-Kincaid Reading Ease score was higher than recommended for patient education materials $(48.8 \pm 15.6$, range $25.2-85.3)$. Overall quality of sources supporting patient decision-making for full-thickness rectal prolapse surgery was poor (median DISCERN score $1 / 5 \pm 1.18$, range $1-5$ ). No sources met
\end{abstract}

G. E. Fowler

gfowler2@sheffield.ac.uk

1 The Medical School, University of Sheffield, Beech Hill Road, Sheffield S10 2RX, UK

2 Department of General Surgery, Sheffield Teaching Hospitals, Sheffield, UK minimum decision-making standards (median IPDASi score $5 / 12 \pm 2.01$, range $1-8)$.

Conclusions Currently, easily accessible online health information to support patient decision-making for rectal surgery is of poor quality, difficult to read and does not support shared decision-making. It is recommended that professional bodies and medical professionals seek to develop decision aids to support decision-making for full-thickness rectal prolapse surgery.

Keywords Rectal prolapse $\cdot$ Surgery $\cdot$ Decision-making · Online resources

\section{Introduction}

Full-thickness rectal prolapse is the protrusion of the rectum beyond the anal canal. Although a benign condition, the symptoms produced by the prolapse can be debilitating and include discomfort, incontinence and constipation [1]. Although conservative management is possible, the condition can only be corrected with surgery [1]. Surgical management aims to correct the prolapse and improve functional issues. Several operations have been described for full-thickness rectal prolapse; all result in restoration of normal anatomy. These operations can be divided into two approaches, perineal and abdominal.

Abdominal approaches are typically used for physically fit patients who can tolerate a general anaesthetic. It is thought that these approaches offer good outcomes [2]. Perineal procedures can be carried out without the need for a general anaesthetic, so they are typically preferred for elderly and more unfit patients. There are concerns that this approach is associated with inferior outcomes when compared to other approaches [1-3]. More recently, improvements in 
anaesthetic techniques and the use of laparoscopic surgery have affected these traditional perceptions. In addition, there are multiple techniques within these groups that have various advantages and disadvantages. For instance, perineal procedures may involve rectal amputation with a potential increased risk of complications, or preservation of the rectum with a higher risk of functional issues. Abdominal procedures may involve a mesh support with the theoretical reduction in incontinence but increased risk of harm. There is also equipoise amongst surgeons as to the optimum approach. The surgical management of full-thickness rectal prolapse is therefore complex, and these considerations need to all be carefully considered with the patient in the shared decision-making process.

Given the relevant trade-offs for each approach and procedure, it is important to take patient preferences into account when planning surgery. The consent paradigm has shifted to encourage a shared-decision model [4]. Surgeons are encouraged to allow time for patients to read further material on their condition and treatment, including accessing online information [4]. It has been shown that around two-thirds of patients go online to seek health information $[5,6]$. It is therefore essential that this information is of high quality, as it can significantly support and improve patients' experiences with decision-making [7]. It has also been documented that the quality of online health information to aid patient decision-making is variable [7-12].

The aim of this study was to assess the readability and quality of online resources to support patient decision-making for full-thickness rectal prolapse surgery.

\section{Materials and methods}

This project was registered (ref CRD42017058319) on the international database PROSPERO (https://www.crd.york. ac.uk/PROSPERO/). The review was reported in concordance with the Preferred Reporting Items for Systematic Reviews and Meta-Analyses (PRISMA) guidance [13]. The methods in this study are adapted from two recent studies assessing the quality of online health information to support patient decision-making in colorectal surgery $[9,10]$.

\section{Search strategy}

Searches were performed on Google (www.google.co.uk; Mountain View, CA, USA) and specialist decision aid repositories, which included the Decision Aids Library Inventory (DALI), NHS Choices, NHS Evidence, Clinical Trials Gateway and the National Guidance Clearing House.

All searches used the following four pre-defined search strings: 'rectal prolapse', 'rectal prolapse surgery', 'rectal prolapse operation' and 'rectal prolapse repair'. These lay searches aimed to capture a typical patient search, an approach adapted from similar studies in colorectal disease $[10,12]$, and expanded from a previous rectal prolapse study [11]. Searches from the repositories included any online decision aids. Searches performed on Google included all sources found on the first two pages, since $92 \%$ of online users do not go beyond the first page [14]. No other search engines were used, as Google is the most popular search engine for accessing online health information [14]. Google searches were done using the 'Incognito window' to avoid the effects of 'Google personalisation', which provides the most relevant results based on your search history [15].

\section{Data extraction}

Data extraction was performed by two authors (GEF and DMB), and any conflicts were resolved by a third author (MJL). Data were extracted onto a Microsoft Excel 2013 (Microsoft, Washington, USA) spreadsheet and included information on the sources URL, upload source, country of origin and descriptions on the management of a full-thickness rectal prolapse, both medical and surgical.

\section{Eligibility criteria}

The extracted data were screened for duplicates, and these sources were subsequently removed. Sources included for full-text analysis were assessed against the following predefined inclusion criteria;

1. Sources with the content about full-thickness rectal prolapse and surgery.

2. Content in English language.

3. Content aimed at patients.

Sources were excluded if they did not meet the inclusion criteria or met any of the following pre-defined exclusion criteria: advertisements, online videos (e.g. YouTube videos), newspaper articles, academic sources not aimed at patients (e.g. PubMed articles) and sources requiring a subscription.

\section{Data analysis}

Sources were analysed according to three measures;

1. The readability using the Flesch-Kincaid Reading Ease score (https://www.webpagefx.com/tools/read-able/). This measures the reading ease, with a score from 0 to 100 corresponding to the education level required to read the information based on the US schools grading system. A low score suggests the text is complicated to 
understand, and a score between 60 and 80 suggests the text is easy to read by a 12- to 15-year-old [16].

2. DISCERN score. The DISCERN instrument is designed to assess the quality of written information on the treatment choices for a defined health problem [17]. The tool consists of 15 questions, each rated on a 5-point scale of 1 (quality criterion not fulfilled), 2-4 (quality criterion partially fulfilled) and 5 (quality criterion completely fulfilled). A global score is also given and is rated on a 3 -point scale of 1 (serious shortcomings), 3 (potentially important shortcomings) or 5 (minimal shortcomings). The score indicates the assessor's overall conclusion about the quality of the source for providing information on the treatment choices for the defined health problem.

3. International Patient Decision Aids Standards (IPDAS) minimum standards criteria score (IPDASi, v4.0). The IPDASi criteria consist of three categories: qualifying, certifying and quality criteria [18]. These categories aid the assessment of patient decision aids. The last category is considered desirable, but not essential for the assessment of patient decision aids, and was therefore excluded from this study, leaving a 12 -item checklist of qualifying and certifying criteria [18].

\section{Results}

\section{Website selection}

The lay search strings found a total of 3,497,000 websites from Google and 7 from the specialist decision aid repositories (Fig. 1). There were 88 sources found from the first two pages of Google, with 53 duplicates removed from Google, or the repositories. This left 42 sources for full-text assessment, of which 18 did not meet the pre-defined eligibility criteria. This left 24 sources for inclusion in the review, all of which were identified through Google. Sources included in the study, and procedures discussed, are presented in Table 1.

\section{Website characteristics}

The website characteristics are summarised in Table 2. The majority of websites were based in the UK $(n=11)$, with the remainder from the USA $(n=8)$, Australia $(n=3)$ or undetermined $(n=2)$. The uploaded sources were healthcare service providers $(n=12)$, patient resources $(n=5)$, public domains $(n=2)$, charities $(n=2)$, governmental or professional organisations $(n=2)$ or other $(n=1)$. Thirteen of these sources described both the medical and surgical treatments, and 11 described only the surgical treatment. Four

Fig. 1 PRISMA flow diagram of search strategy

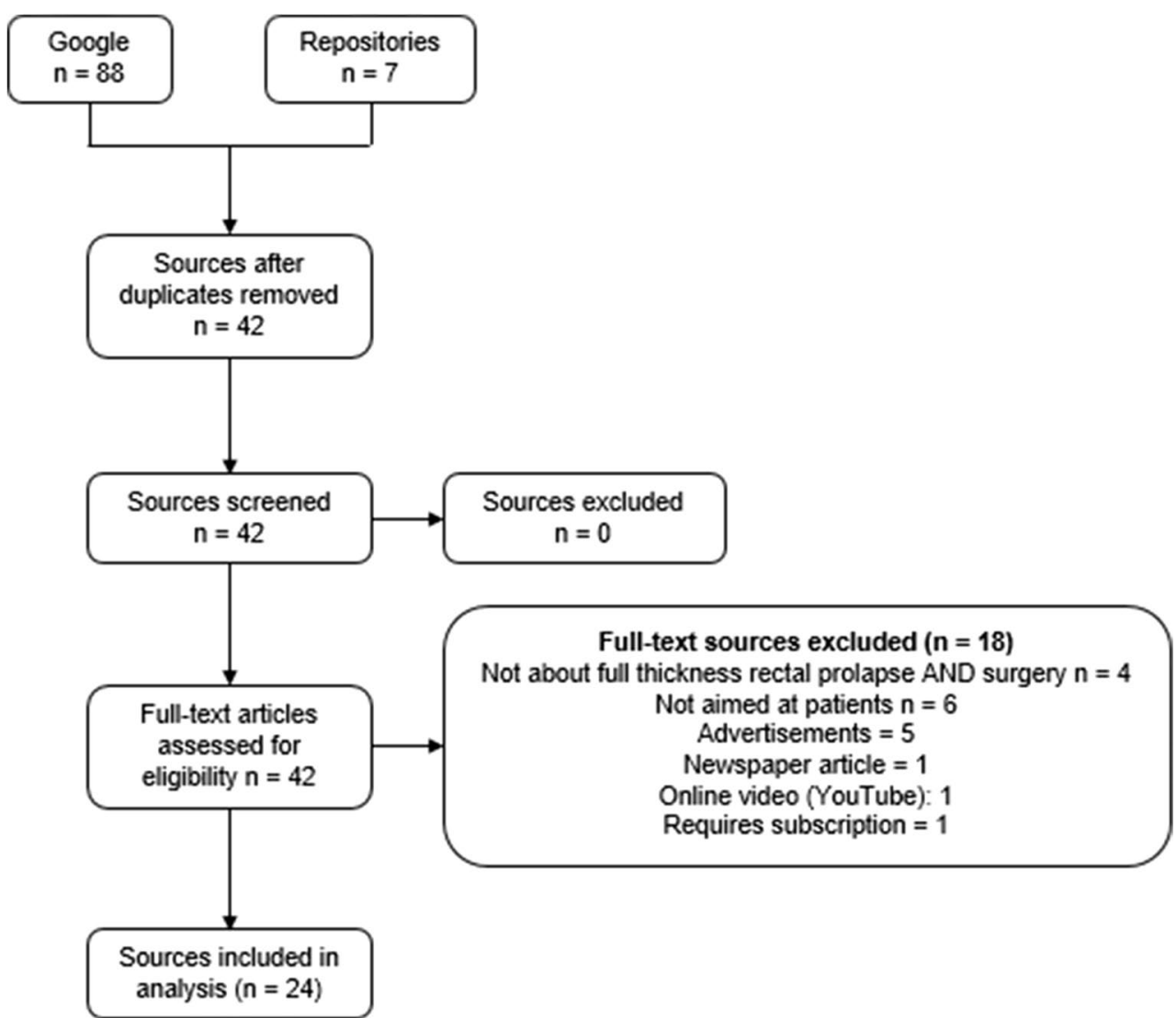




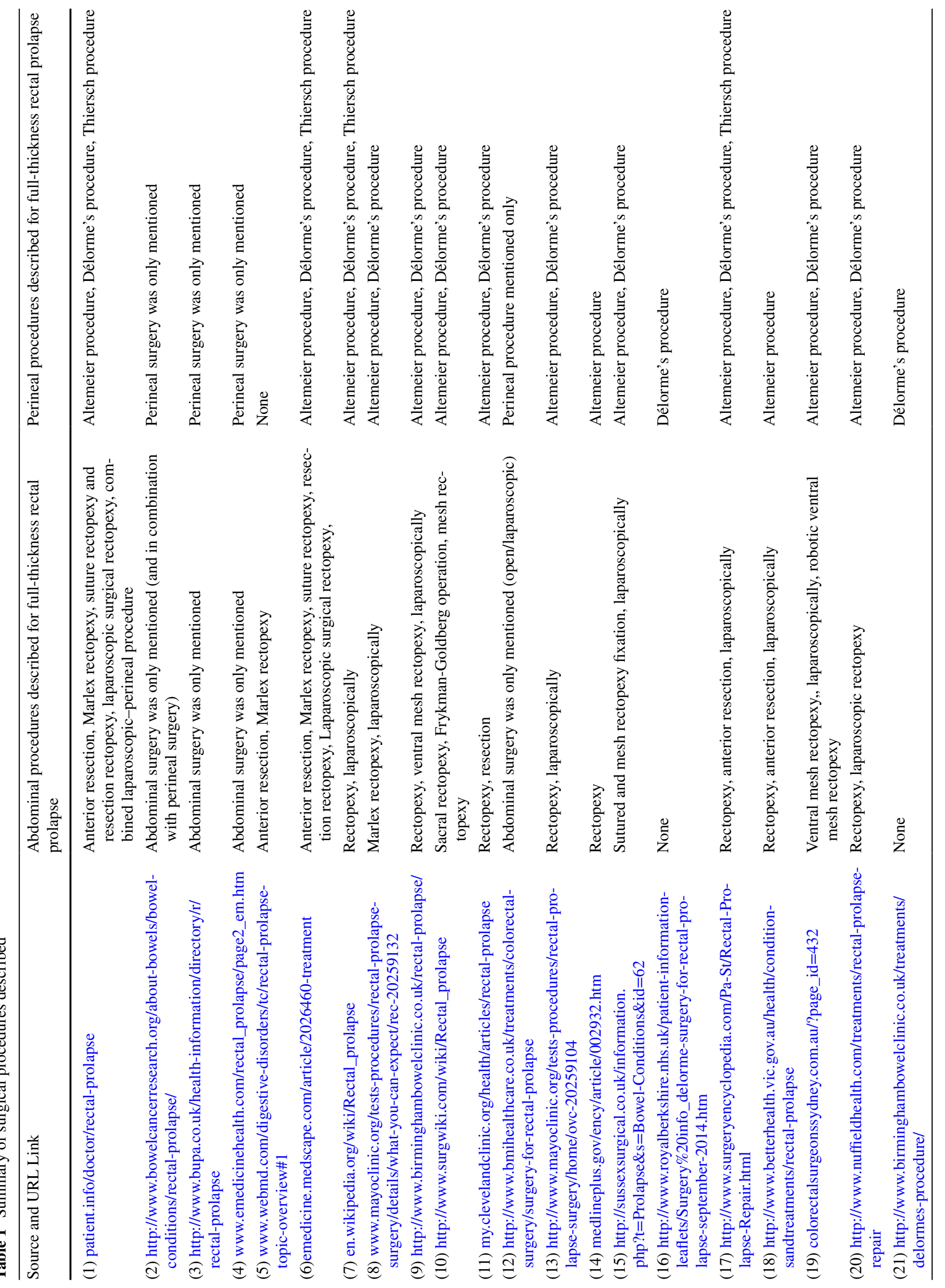


of the latter stated explicitly the consequences for a patient deciding not to have surgery.

\section{Readability}

The mean Flesch-Kincaid Reading Ease score was 48.8 (SD \pm 15.6 , range 25.2-85.3) out of 100, representing a reading level expected at university [16]. This is higher than recommended for patient education materials, which recommends a score between 80 and 100 [19].

\section{DISCERN score}

The DISCERN scores are presented on a visual analogue scale in Table 3. Scores of 1, 3 and 5, respectively, indicate whether the source met none, partially met or all of the criteria to the question. The overall quality of online resources on treatment choices for full-thickness rectal prolapse were poor in this study, with a median DISCERN score of $1 / 5$ ( $\mathrm{SD} \pm 1.18$, range $1-5)$ out of 5 . Only one source scored highly on its overall quality (5/5). This was uploaded by the American Society of Colon and Rectal Surgeons (source 24). All other sources scored poorly in their overall quality, meeting none of the criteria in several of the domains. Only $11 / 24$ sources partially met all of the criteria (overall quality score of 3/5), and with the exception of one source (16), none of eleven sources provided clear aims or achieved their aims. This highlights serious or potentially important shortcomings on the written information on treatment choices for full-thickness rectal prolapse.

Generally, the sources scored poorly on questions important for shared decision-making (questions 12, 13 and 15), including on how the treatment choice will affect overall quality of life and the consequences of not choosing a treatment. On the latter, only three sources scored highly $(5 / 5$, sources 3-4 and 24). Domains which scored more highly were questions on how the treatment works, the benefits and risks of each and for providing more than one treatment choice (questions 9, 10, 11 and 14). There were two sources ( 9 and 14) which scored poorly (1/5) in all domains. They were surgically focused private healthcare resources and provided no descriptions on the medical management of full-thickness rectal prolapse.

\section{IPDASi (v4.0) minimum standards criteria}

The IPDASi scores are shown in Table 4. A check mark indicates whether the criteria have been met, producing a total score out of 12 . All criteria should be met to be in concordance with IPDAS recommendations to meet minimum decision-making standards [18]. The median IPDASi score was $5 / 12(\mathrm{SD} \pm 2.01$, range $1-8)$, with none of the sources meeting all of the criteria, or describing the experience of 
Table 2 Summary of website characteristics and Flesch-Kincaid Reading Ease scores

\begin{tabular}{|c|c|c|c|c|}
\hline Source and URL Link & Upload source & $\begin{array}{l}\text { Country } \\
\text { of origin }\end{array}$ & $\begin{array}{l}\text { Described treatment } \\
\text { (medical/surgical/ } \\
\text { both) }\end{array}$ & $\begin{array}{l}\text { Flesch-Kincaid } \\
\text { Reading Ease } \\
\text { Scores }\end{array}$ \\
\hline (1) patient.info/doctor/rectal-prolapse & Patient & UK & Both & 42.6 \\
\hline $\begin{array}{l}\text { (2) http://www.bowelcancerresearch.org/ } \\
\text { about-bowels/bowel-conditions/rectal- } \\
\text { prolapse/ }\end{array}$ & Bowel and Cancer Research & UK & Both & 66.8 \\
\hline $\begin{array}{l}\text { (3) http://www.bupa.co.uk/health-informa- } \\
\text { tion/directory/r/rectal-prolapse }\end{array}$ & Bupa & UK & Both & 61.4 \\
\hline $\begin{array}{l}\text { (4) www.emedicinehealth.com/rectal_pro- } \\
\text { lapse/page2_em.htm }\end{array}$ & eMedicineHealth & USA & Both & 52.8 \\
\hline $\begin{array}{l}\text { (5) www.webmd.com/digestive-disorders/tc/ } \\
\text { rectal-prolapse-topic-overview\#1 }\end{array}$ & WebMD & USA & Both & 62.3 \\
\hline $\begin{array}{l}\text { (6) emedicine.medscape.com/ } \\
\text { article/2026460-treatment }\end{array}$ & Medscape & USA & Both & 29.7 \\
\hline (7)en.wikipedia.org/wiki/Rectal_prolapse & Wikipedia & N/A & Both & 39.7 \\
\hline $\begin{array}{l}\text { (8) www.mayoclinic.org/tests-procedures/ } \\
\text { rectal-prolapse-surgery/details/what-you- } \\
\text { can-expect/rec-20259132 }\end{array}$ & Mayo Clinic & USA & Surgical & 48.5 \\
\hline $\begin{array}{l}\text { (9) http://www.birminghambowelclinic. } \\
\text { co.uk/rectal-prolapse/ }\end{array}$ & Birmingham Bowel Clinic & UK & Surgical & 31.5 \\
\hline $\begin{array}{l}\text { (10) http://www.surgwiki.com/wiki/Rec- } \\
\text { tal_prolapse }\end{array}$ & SurgWiki & AUS & Both & 29.2 \\
\hline $\begin{array}{l}\text { (11) my.clevelandclinic.org/health/articles/ } \\
\text { rectal-prolapse }\end{array}$ & Cleveland Clinic & USA & Both & 48.7 \\
\hline $\begin{array}{l}\text { (12) http://www.bmihealthcare.co.uk/ } \\
\text { treatments/colorectal-surgery/surgery-for- } \\
\text { rectal-prolapse }\end{array}$ & BMI Healthcare & UK & Surgical & 55.8 \\
\hline $\begin{array}{l}\text { (13) http://www.mayoclinic.org/tests- } \\
\text { procedures/rectal-prolapse-surgery/home/ } \\
\text { ovc-20259104 }\end{array}$ & Mayo Clinic & USA & Surgical & 47.7 \\
\hline $\begin{array}{l}\text { (14) medlineplus.gov/ency/article/002932. } \\
\text { htm }\end{array}$ & Medline Plus & USA & Surgical & 56.8 \\
\hline $\begin{array}{l}\text { (15) http://sussexsurgical.co.uk/infor- } \\
\text { mation.php?t=Prolapse\&s=Bowel- } \\
\text { Conditions\&id=62 }\end{array}$ & Sussex Surgical & UK & Surgical & 34.5 \\
\hline $\begin{array}{l}\text { (16) http://www.royalberkshire.nhs.uk/ } \\
\text { patient-information-leaflets/Surgery } \% 20 \\
\text { info_delorme-surgery-for-rectal-prolapse- } \\
\text { september-2014.htm }\end{array}$ & Royal Berkshire NHS Foundation Trust & UK & Surgical & 70.7 \\
\hline $\begin{array}{l}\text { (17) http://www.surgeryencyclopedia.com/ } \\
\text { Pa-St/Rectal-Prolapse-Repair.html }\end{array}$ & Encyclopedia of Surgery & - & Both & 70.9 \\
\hline $\begin{array}{l}\text { (18) http://www.betterhealth.vic.gov.au/ } \\
\text { health/conditionsandtreatments/rectal- } \\
\text { prolapse }\end{array}$ & Better Health Channel & AUS & Both & 25.2 \\
\hline $\begin{array}{l}\text { (19) colorectalsurgeonssydney.com. } \\
\text { au/?page_id }=432\end{array}$ & Colorectal Surgeons Sydney & AUS & Both & 39.0 \\
\hline $\begin{array}{l}\text { (20) http://www.nuffieldhealth.com/treat- } \\
\text { ments/rectal-prolapse-repair }\end{array}$ & Nuffield Health & UK & Both & 56.8 \\
\hline $\begin{array}{l}\text { (21) http://www.birminghambowelclinic. } \\
\text { co.uk/treatments/delormes-procedure/ }\end{array}$ & Birmingham Bowel Clinic & UK & Surgical & 39.2 \\
\hline $\begin{array}{l}\text { (22) www.bladderandbowelfoundation.org/ } \\
\text { bowel/bowel-treatments/rectal-prolapse- } \\
\text { repair/ }\end{array}$ & Bladder \& Bowel Community & UK & Surgical & 30.7 \\
\hline
\end{tabular}


Table 2 (continued)

\begin{tabular}{|c|c|c|c|c|}
\hline Source and URL Link & Upload source & $\begin{array}{l}\text { Country } \\
\text { of origin }\end{array}$ & $\begin{array}{l}\text { Described treatment } \\
\text { (medical/surgical/ } \\
\text { both) }\end{array}$ & $\begin{array}{l}\text { Flesch-Kincaid } \\
\text { Reading Ease } \\
\text { Scores }\end{array}$ \\
\hline $\begin{array}{l}\text { (23) www.royalberkshire.nhs.uk/patient- } \\
\text { information-leaflets/Surgery_Lapar- } \\
\text { ascopic\%20keyhole\%20rectopexy\%20 } \\
\text { rectal\%20repair\%20surgery\%20sept } \% 20 \\
\text { 2014.htm }\end{array}$ & $\begin{array}{l}\text { Royal Berkshire Hospital (NHS Foundation } \\
\text { Trust) }\end{array}$ & UK & Surgical & 85.3 \\
\hline $\begin{array}{l}\text { (24) http://www.fascrs.org/patients/disease- } \\
\text { condition/rectal-prolapse-expanded- } \\
\text { version }\end{array}$ & $\begin{array}{l}\text { American Society of Colon and Rectal } \\
\text { Surgeons }\end{array}$ & USA & Surgical & 45.5 \\
\hline
\end{tabular}

Table 3 DISCERN Scores

\begin{tabular}{|c|c|c|c|c|c|c|c|c|c|c|c|c|c|c|c|c|c|c|c|c|c|c|c|c|}
\hline The DISCERN Instrument & 1 & 2 & 3 & 4 & 5 & 6 & 7 & 8 & 9 & 10 & 11 & 12 & 13 & 14 & 15 & 16 & 17 & 18 & 19 & 20 & 21 & 22 & 23 & 24 \\
\hline 1. Are the aims clear? & 1 & 1 & 1 & 1 & 1 & 1 & 1 & 1 & 1 & 1 & 1 & 1 & 1 & 1 & 1 & 5 & 1 & 1 & 1 & 1 & 1 & 1 & 5 & 5 \\
\hline 2. Does it achieve its aims? & 1 & 1 & 1 & 1 & 1 & 1 & 1 & 1 & 1 & 1 & 1 & 1 & 1 & 1 & 1 & 5 & 1 & 1 & 1 & 1 & 1 & 1 & 5 & 5 \\
\hline 3. Is it relevant? & 4 & 4 & 5 & 4 & 3 & 5 & 4 & 2 & 1 & 2 & 3 & 1 & 1 & 3 & 2 & 4 & 4 & 3 & 3 & 2 & 2 & 1 & 3 & 5 \\
\hline $\begin{array}{l}\text { 4. Is it clear what sources of information were } \\
\text { used to compile the publication? }\end{array}$ & 5 & 1 & 3 & 3 & 1 & 4 & 5 & 1 & 1 & 1 & 4 & 1 & 1 & 4 & 1 & 2 & 3 & 1 & 3 & 1 & 1 & 1 & 2 & 5 \\
\hline $\begin{array}{l}\text { 5. Is it clear when the information used or } \\
\text { reported in the publication was produced? }\end{array}$ & 5 & 1 & 1 & 3 & 1 & 3 & 4 & 1 & 1 & 3 & 3 & 1 & 1 & 2 & 1 & 2 & 1 & 2 & 1 & 1 & 1 & 1 & 2 & 3 \\
\hline 6. Is it balanced and unbiased? & 5 & 3 & 5 & 5 & 5 & 5 & 5 & 2 & 1 & 4 & 5 & 1 & 1 & 4 & 3 & 3 & 1 & 5 & 5 & 1 & 1 & 1 & 3 & 5 \\
\hline $\begin{array}{l}\text { 7. Does it provide details of additional sources } \\
\text { of support and information? }\end{array}$ & 5 & 1 & 2 & 3 & 1 & 1 & 1 & 1 & 1 & 1 & 1 & 1 & 1 & 1 & 1 & 1 & 5 & 2 & 1 & 1 & 1 & 1 & 1 & 2 \\
\hline 8. Does it refer to areas of uncertainty? & 2 & 2 & 1 & 1 & 1 & 5 & 3 & 1 & 1 & 4 & 1 & 1 & 1 & 1 & 1 & 1 & 1 & 2 & 1 & 1 & 1 & 1 & 1 & 3 \\
\hline 9. Does it describe how each treatment works? & 2 & 5 & 5 & 3 & 5 & 5 & 4 & 1 & 1 & 5 & 5 & 1 & 1 & 5 & 5 & 2 & 5 & 5 & 5 & 5 & 1 & 1 & 2 & 5 \\
\hline $\begin{array}{l}\text { 10. Does it describe the benefits of each } \\
\text { treatment? }\end{array}$ & 2 & 5 & 5 & 5 & 1 & 5 & 2 & 1 & 1 & 5 & 3 & 1 & 1 & 2 & 2 & 3 & 5 & 3 & 5 & 1 & 1 & 1 & 3 & 3 \\
\hline $\begin{array}{l}\text { 11. Does it describe the risks of each } \\
\text { treatment? }\end{array}$ & 2 & 3 & 3 & 5 & 1 & 5 & 5 & 1 & 1 & 5 & 4 & 1 & 1 & 3 & 3 & 3 & 5 & 4 & 5 & 3 & 3 & 1 & 4 & 5 \\
\hline $\begin{array}{l}\text { 12. Does it describe what would happen if no } \\
\text { treatment is used? }\end{array}$ & 1 & 1 & 5 & 5 & 1 & 3 & 1 & 1 & 1 & 1 & 1 & 1 & 1 & 1 & 1 & 2 & 1 & 1 & 1 & 1 & 1 & 1 & 1 & 5 \\
\hline $\begin{array}{l}\text { 13. Does it describe how the treatment choices } \\
\text { affect overall quality of life? }\end{array}$ & 1 & 1 & 1 & 2 & 1 & 2 & 3 & 1 & 1 & 1 & 1 & 1 & 1 & 1 & 1 & 1 & 2 & 1 & 1 & 1 & 1 & 1 & 2 & 2 \\
\hline $\begin{array}{l}\text { 14. Is it clear that there may be more than one } \\
\text { possible treatment choice? }\end{array}$ & 5 & 5 & 5 & 5 & 5 & 5 & 5 & 1 & 1 & 5 & 5 & 2 & 1 & 5 & 5 & 3 & 5 & 5 & 5 & 3 & 5 & 3 & 2 & 5 \\
\hline $\begin{array}{l}\text { 15. Does it provide support for shared } \\
\text { decision-making? }\end{array}$ & 1 & 1 & 1 & 1 & 1 & 1 & 1 & 1 & 1 & 1 & 1 & 1 & 1 & 1 & 1 & 1 & 1 & 1 & 1 & 1 & 1 & 1 & 1 & 2 \\
\hline 16. Overall quality (out of 5) & 3 & 1 & 3 & 3 & 1 & 3 & 3 & 1 & 1 & 3 & 3 & 1 & 1 & 1 & 1 & 3 & 3 & 3 & 3 & 1 & 1 & 1 & 1 & 5 \\
\hline
\end{tabular}

The colour of the square visually represents the DISCERN score for each domain for a particular source: red $=5$, dark orange $=4$, orange $=3$, pale orange $=2$, green $=1$

the consequence of treatment options (criteria 6), or providing a publication date (criteria 9). Domains which scored more highly included descriptions of the health condition (21/24 sources), the treatment options (22/24 sources), with pros and cons (16/24 and 17/24, respectively), while sources which scored the poorest in all of the IPDASi minimum standards criteria (1/12) were surgically focused (12, 21-22). There were only five sources $(1,6-7,13,24)$ which provided citation to their evidence, and this included the four sources $(1,6-7,24)$ which had the highest IPDASi minimum standards criteria scores, of which three of the four $(1,6-7)$ described both the medical and surgical treatments for fullthickness rectal prolapse.

\section{Discussion}

This study has systematically assessed the readability and quality of online health resources to support patient decision-making for full-thickness rectal prolapse surgery. Of these sources, the average readability was higher than recommended for patient education materials, and none met minimum decision-making standards.

The overall poor quality is consistent with findings presented by Sehgal et al. [11], which reported the poor quality of online patient information for full-thickness rectal prolapse, but based results on the DISCERN instrument alone. The data from our study are of additional value, as it also 


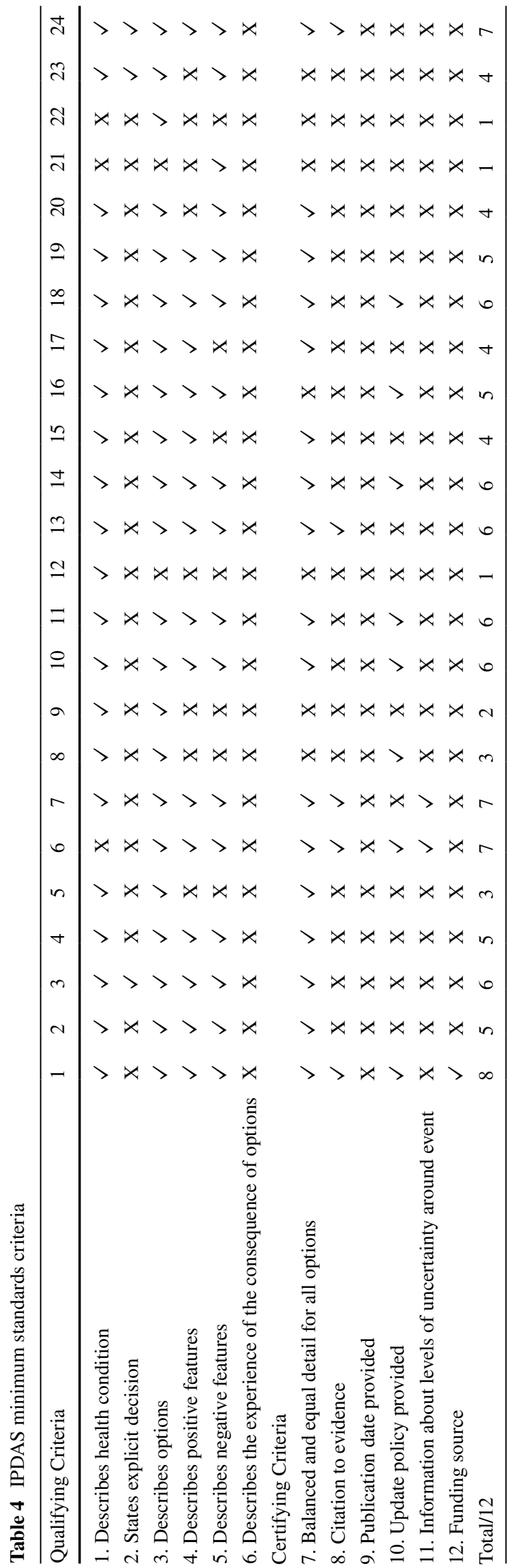

provides the additional dimensions of Flesch-Kincaid Reading Ease and IPDASi scores.

Poor quality of online health information about other conditions including breast cancer [7], perianal Crohn's fistula [9] and ulcerative colitis [10] has been reported. This is concerning, as patients may trust in these sources of information. A European survey found $90 \%$ of patients were satisfied with online health information, with only a small percentage (10\%) not satisfied on the grounds of reliability, commercially orientated or not enough detail [6].

In our study, private healthcare resources describing only the surgical management of full-thickness rectal prolapse had the poorest quality of written information, indicated by low DISCERN and IPDAS scores and high Flesch-Kincaid Reading Ease scores. In addition, these sources did not support shared decision-making, as seen in previous work [7, 9-11]. Only one source evaluated by the DISCERN instrument was of high overall quality, but remained difficult to read. The source was provided by the American Society of Colon and Rectal Surgeons. Although this may seem an obvious source of reliable information by healthcare professionals, this may be less obvious to patients.

An online decision aid to support patient decision-making for full-rectal prolapse surgery although perhaps desirable is nevertheless difficult to create for rectal prolapse since the management may be complex, and many of the surgical decisions are based on surgical dogma rather than evidence base [1]. The consultation is therefore still the most powerful tool to support patient decision-making for full-thickness rectal prolapse, as the online health information is currently of poor quality and not commonly read by the patients likely to present with this condition.

This study has some limitations. Online videos were not analysed despite their increasing popularity as a source of patient information [20]. Their popularity for the patients likely to present with a full-thickness rectal prolapse is not yet reported and is presumably even less commonly used than written online health information. We only used the search engine Google as there is evidence that Google incorporates the vast majority of websites found from other search engines [21]. Restricting the searches to only the first two pages of Google was another limitation. However, most online users do not go beyond the first page [14]. There are also limitations from using the DISCERN instrument. It may overestimate the overall quality of online health information to support patient decision-making [9, 10]. Sources scored highly if they mentioned more than one possible treatment option, but can also score highly if they mention only one other treatment option, without reference to medical alternatives, or explaining the pros and cons of the other treatment option. A particular issue with rectal prolapse and online health information is the age distribution of the condition. Most patients are elderly with a peak incidence in the 
seventh decade [1]. Only a small portion of patients above the age of 55 use online health information [6].

Conversely, our study has several strengths. To our knowledge, it is the first systematic review of online resources to support patient decision-making for full-thickness rectal prolapse surgery to have followed PRISMA guidance and provided Flesch-Kincaid Reading Ease and IPDASi scores.

Clearly, there is work to be done to improve patient information. Professional organisations should engage with patients to understand their information needs and develop an appropriate resource to support this. This could take the form of a simple leaflet, an option matrix or an online decision support tool. Other work to explore patient values and 'trade-offs' would make this of more use to support patients. In the meantime, clinicians should identify a reliable online resource for the condition and guide patients towards this.

\section{Conclusions}

Easily accessible online health information to support patient decision-making for rectal surgery is of poor quality, difficult to read and does not support shared decision-making. It is recommended that professional bodies and medical professionals seek to develop decision aids to support decision-making for full-thickness rectal prolapse surgery and in other areas of medicine.

\section{Compliance with ethical standards}

Conflict of interest The authors declare that they have no conflict of interest.

Ethical approval This study did not involve human participants and/ or animals by any of the authors.

Informed consent For this type of study informed consent is not required.

Open Access This article is distributed under the terms of the Creative Commons Attribution 4.0 International License (http://creativecommons.org/licenses/by/4.0/), which permits unrestricted use, distribution, and reproduction in any medium, provided you give appropriate credit to the original author(s) and the source, provide a link to the Creative Commons license, and indicate if changes were made.

\section{References}

1. Varma M, Rafferty J, Buie WD (2011) Practice parameters for the management of rectal prolapse. Dis Colon Rectum 54(11):13391346. https://doi.org/10.1097/DCR.0b013e3182310f75

2. Madiba TE, Baig MK, Wexner SD (2005) Surgical management of rectal prolapse. Arch Surg 140:63-73. https://doi.org/10.1001/ archsurg.140.1.63
3. Shin (2011) Surgical treatment of rectal prolapse. J Korean Soc Coloproctol 27(1):5-12. https://doi.org/10.3393/jksc.2011.27.1.5

4. Royal College of Surgeons England (2016) Consent: Supported decision-making - a good practice guide. https://www.rcseng. ac.uk/library-and-publications/college-publications/docs/consentgood-practice-guide/. Accessed 5 June 2017

5. Fox S (2011) Health Topics: $80 \%$ of internet users look for health information online. http://www.pewinternet.org/files/old-media/ Files/Reports/2011/PIP_Health_Topics.pdf. Accessed 5 June 2017

6. European Commission (2014) Europeans becoming enthusiastic users of online health information. https://ec.europa.eu/digital-single-market/news/europeans-becoming-enthusiastic-users-onlinehealth-information. Accessed 5 June 2017

7. Bruce JG, Tucholka JL, Steffens NM, Neuman HB (2015) Quality of online information to support patient decision-making in breast cancer surgery. J Surg Oncol 112(6):575-580. https://doi. org $/ 10.1002 /$ jso. 24046

8. Chung M, Oden RP, Joyner BL, Sims A, Moon RY (2012) Safe infant sleep recommendations on the internet: let's Google it. J Pediatr 161(6):1080-1084. https://doi.org/10.1016/j. jpeds.2012.06.004

9. Marshall JH, Baker DM, Lee MJ, Jones GL, Lobo AJ, Brown SR (2017) Assessing internet-based information used to aid patient decision-making about surgery for perianal Crohn's fistula. Tech Coloproctol 21(6):461-469. https://doi.org/10.1007/ s10151-017-1648-2

10. Baker DM, Marshall JH, Lee MJ, Jones GL, Brown SR, Lobo AJ (2017) A Systematic Review of Internet Decision-Making Resources for Patients Considering Surgery for Ulcerative Colitis. Inflamm Bowel Dis 23(8):1293-1300. https://doi.org/10.1097/ MIB.0000000000001198

11. Sehgal A, Scott FAM, Joshi HM, Gosselink MP (2016) Quality of patient information online for rectal prolapse. Tech Coloproctol 20(5):333-335. https://doi.org/10.1007/s10151-016-1434-6

12. van der Marel S, Duijvestein M, Hardwick JC et al (2009) Quality of web-based information on inflammatory bowel diseases. Inflamm Bowel Dis 15(12):1891-1896. https://doi.org/10.1002/ ibd.20976

13. Moher D, Liberati A, Tetzlaff J, Altman DG (2009) Preferred Reporting items for systematic reviews and meta- analyses: the PRISMA statement (Reprinted from Annals of Internal Medicine). Phys Ther 89(9):873-880

14. van Deursen AJ (2012) Internet skill-related problems in accessing online health information. Int J Med Inform 81:61-72. https://doi. org/10.1016/j.ijmedinf.2011.10.005

15. Google. Personalized search for everyone $2017 \mathrm{https} / / /$ googleblog. blogspot.co.uk/2009/12/personalized-search-for-everyone.html. Accessed 5 June 2017

16. University of Canterbury. How to write plain English. http:// www.mang.canterbury.ac.nz/writing_guide/writing/flesch.shtml. Accessed 5 June 2017

17. Charnock (1998) The DISCERN Handbook: Quality criteria for consumer health information on treatment choices. University of Oxford and The British Library http://www.discern.org.uk/discern.pdf. Accessed 5 June 2017

18. Joseph-Williams N, Newcombe R, Politi M et al (2014) Toward Minimum Standards for Certifying Patient Decision Aids. Med Decis Making 34(6):699-710. https://doi.org/10.1177/02729 89X13501721

19. Cotugna N, Vickery CE, Carpenter-Haefele KM (2005) Evaluation of literacy level of patient education pages in health-related journals. J Community Health 30(3):213-219

20. Brooks FM, Lawrence H, Jones A, McCarthy MJ (2014) YouTube $^{\mathrm{TM}}$ as a source of patient information for lumbar discectomy. 
Ann R Coll Surg Engl 96(2):144-146. https://doi.org/10.1308/00 $3588414 X 13814021676396$

21. Shital Kiran DP, Bargale S, Pandya P et al (2015) Evaluation of Health on the Net seal label and DISCERN as content quality indicators for patients seeking information about thumb sucking habit. J Pharm Bioallied Sci 7(Suppl 2):S481-S485. https://doi. org/10.4103/0975-7406.163509 